\title{
Evidence-based medicine should be based on science
}

To the Editor: Although the recent article in the SAMJ entitled 'Evidence-based medicine - are we boiling the frog?' by Muckart ${ }^{[1]}$ can evoke a true discussion, I feel that it could worsen the prejudice some people already have regarding evidence-based medicine (EBM).

While I understand and concur with most of Muckart's sentiments, I am concerned about the army of enthusiastic practitioners of complementary and alternate medicine (CAM) reading this - unscientific people without logic, reason or objectivity. These people (practitioners of homoeopathy, naturopathy, etc.) peddle snake-oil treatments for disease and look to criticise orthodox (read 'ethical') medicine. They continuously denigrate the concept of randomised control trials (RCTs), and denounce EBM.

Whilst orthodox medicine might 'need to get its house in order' as Muckart implies (regarding data fabrication, etc.), it is not needed nearly as much as it is in the area of CAM.

It therefore occurred to me that an article such as this could favour the claims such practitioners make, and encourage their legitimacy, facilitating entry into mainstream medicine 'through the back door'.

At a time when scientific medicine is literally losing the war against quackery at every level, one finds that even academic medical faculties remain apathetic, and what was quackery or pseudoscience is now merely considered 'unconventional' or 'complementary'.

I agree that we should not look at statistical significance, without looking at scientific plausibility. Muckart mentions that evidence might not be synonymous with truth, but scientific implausibility cannot possibly be reconciled with either. What we need to do is embrace science-based medicine (which in turn encompasses EMB). And, yes, this should always be patient-based.

Muckart's quoting of Osler: 'the good physician treats disease, the great one treats the patient', does not of course mean that the two concepts are mutually exclusive.

There are flaws to EBM but the emphasis should be on good science. It never occurred to the pioneers of EBM that anyone would consider performing a clinical trial that may not pass scientific plausibility.

EBM should not be restricted to RCTs and metaanalyses, but it should track down the best science-based evidence with which to answer our clinical questions. Plausibility should be based on science!

\section{Gideon Peter Tunguy-Desmarais}

Umhlanga Medical Centre, Umhlanga, South Africa peterent@iafrica.com

1. Muckart DJJ. Evidence-based medicine - are we boiling the frog? S Afr Med 2013;103(7):447-448. [http://dx.doi.org/10.7196/samj.6805]

Muckart responds: I thank Dr Tunguy-Desmarais for his interest in my article concerning EBM.

While I share his concerns regarding certain varieties of CAM, I do not believe that my article alone will fuel the fire of CAM proponents, nor do I concur entirely with his views on their practice.

With regard to the former, I am not alone in voicing concern regarding the limitations of EBM and there are 
a growing number of publications expressing similar sentiments, some from well-known advocates of EBM. ${ }^{[1-3]}$ All emphasise that critical appraisal and an open mind are essential when interpreting the current scientific literature. The same holds true with regard to the results of alternative medicine, and the prejudice of alternative practitioners against EBM, to which Dr Tunguy-Desmarais alludes, may apply equally in reverse. That there is no scientifically plausible explanation for CAM's beneficial effect does not mean they should be dismissed outright.

The analogy of CAM to 'snake oil' treatments and the inference that all such practices are unethical and 'through the back door' is a misrepresentation of the facts. In 2005, the General Medical Council published the Smallwood report ${ }^{[4]}$ on the role of CAM in the National Health Service (NHS), a 193-page assessment of CAM, which included acupuncture, homeopathy, manipulative therapy, and herbal medicine. The report concluded that in certain diseases where conventional medicine had failed, alternative therapies had enjoyed success and should be offered to patients. Admission therefore would be through the front rather than back door.

Lack of scientific evidence is not synonymous with proof of the absence of benefit. As suggested by the French physician Armand Trousseau, 'Medicine consists of science and art in a certain relationship to each other, yet wholly distinct. Science can be learned by anyone, even the mediocre. Art, however, is a gift from heaven.'

\section{J J Muckart}

Nelson R Mandela School of Medicine, University of KwaZulu-Natal, Durban, South Africa davidmuc@ialch.co.za

1. Heneghan C, Godlee F. Where next for evidence based healthcare? BMJ 2013;346:7766. [http://dx.doi. org/10.1136/bmj.f766]

2. Seshia SS, Young GB. The evidence-based medicine paradigm: Where are we 20 years later? Part 1. Can J Neurol Sci 2013;40:465-474.

3. Seshia SS, Young GB. The evidence-based medicine paradigm: Where are we 20 years later? Part 2. Can J Neurol Sci 2013:40:475-481.

4. Smallwood C; Freshminds. The Role of Complementary and Alternative Medicine in the NHS London: General Medical Council, 2005. http://www.getwelluk.com/uploadedFiles/Publications/ SmallwoodReport.pdf (accessed 5 September 2013). 